\title{
VISUOMENĖJE İGYTOS SUAUGUSIŲJŲ PNEUMONIJOS RIZIKOS VEIKSNIAI
}

\author{
Ilja Skalskis, Sigitas Filipauskas, Gintarè Gečaitė \\ Lietuvos sveikatos mokslu universiteto Medicinos akademija, Medicinos fakultetas
}

Raktažodžiai: visuomenèje igyta pneumonija, pneumonija, rizikos veiksniai, suaugusieji.

\begin{abstract}
Santrauka
Darbo tikslas - ivertinti, susisteminti ir išanalizuoti mokslinejje literatūroje pateikiamus duomenis apie visuomeneje igytos suaugusiujų pneumonijos epidemiologiją ir rizikos veiksnius. Šioje sistemineje apžvalgoje išanalizuoti 22 viso teksto straipsniai. Remiantis atrinktų straipsnių rezultatų duomenimis, galime teigti, kad visuomenejje iggytą pneumoniją lemia nemažai koreguojamų ir nekoreguojamų rizikos veiksnių. Greitas modifikuojamų rizikos veiksnių ìvertinimas ir korekcija galètų sumažinti sergamumą visuomenèje igyta suaugusiujų pneumonija ir mirštamumą, ypač pagyvenusių žmonių.
\end{abstract}

\section{İvadas}

Mūsų atliktai literatūros apžvalgai atrinkti stebèjimo tyrimai, kurių pagrindinis rezultatas buvo ịvertinti visuomenèje igytos pneumonijos (toliau - VİP) riziką tiek hospitalizuotiems, tiek ambulatoriškai gydomiems suaugusiems pacientams, kuriems nustatyta radiologiškai patvirtinta pneumonija, apžvelgti VĮP epidemiologiją pasaulyje ir Lietuvoje. Amžius, rūkymas, aplinkos poveikis, buvusi VỊP, lètinès kvejpavimo takų ligos, bloga dantų sveikata, imuninę sistemą slopinantys vaistai yra pagrindiniai VỊP rizikos veiksniai. Nepaisant daugelio plačios apimties tyrimų, pagerejjusios sveikatos priežiūros ir pažangių gydymo antimikrobiniais vaistais galimybių, per pastaruosius dešimtmečius mirtingumas nuo VỊP nesumažèjo [1]. Tikslinès rizikos mažinimo intervencijos, pagrịstos VİP rizikos veiksnių supratimu ir pripažinimu, yra ypač svarbios, mažinant su VỊP susijusị mirčių skaičių [2].

Darbo tikslas - išanalizuoti ir aptarti ịrodymais pagrịstą informaciją apie visuomenejje igytos pneumonijos rizikos veiksnius ir jų poveikị ligos išsivystymui.

\section{Tyrimo medžiaga ir metodai}

Taikyta sisteminè mokslinès literatūros bei dokumentų apžvalga ir analizè. Duomenų buvo ieškoma PubMed, Google Scholar, Up ToDate bei Cochrane duomenų bazėse. Visateksčiai straipsniai atrinkti, jei jų pavadinimas, santrauka ar reikšminiai žodžiai rodè, kad tyrimas tinkamas įtraukti ị šią apžvalgą. Pasirinktos tik anglų kalba skelbtos publikacijos. Vartoti nurodyti raktažodžiai. Atrinkti, išanalizuoti ir apibendrinti 22 straipsniai.

\section{Tyrimo rezultatai}

Epidemiologija. Pneumonija yra dažnai pasitaikanti apatinių kvèpavimo takų infekcija, ypač skubiosios pagalbos skyriuose, lemianti reikšmingą pacientų sergamumą ir mirštamumą. VI̦P apibrěžiama kaip ūminè plaučių infekcija, apimanti alveoles, pasireiškianti pacientui, kuris neseniai buvo gydomas sveikatos priežiūros ịstaigoje [3]. Pneumonija yra trečioji pagrindinè priežastis, dèl kurios JAV kasmet hospitalizuojama 544000 ligonių [4]. VỊP Jungtinèse Valstijose yra pagrindinè sepsio ir mirties nuo infekcijos priežastis [5]. VĮP - svarbi sergamumo ir mirštamumo priežastis išsivysčiusiose šalyse [2]. İprastinès konjuguotos pneumokokinès vakcinos vartojimas vaikams suformavo bendruomenès imunitetą, todèl sumažejo suaugusiujų pneumonijos dažnis [6]. Bendroje suaugusiųjų populiacijoje metinis VỊP dažnis svyruoja nuo 1,6 iki 13,4 susirgimų 1000 gyventojų, 22-51 proc. sergančiujų reikalinga stacionarinè priežiūra, mirštamumas - 3-24 procentai. Mirštamumas kasmet svyruoja nuo 0,1 iki 0,7 iš 1000 žmonių [2]. Higienos instituto duomenimis, Lietuvoje 2019 metais sergančiujų pneumonija buvo 45232, mirtingumas $-1,2$ procento [7]. Atsižvelgiant į VİP paplitimą ir jos galimybes sukelti sunkią daugialypę būklę, sveikatos priežiūros specialistai turi gerai išmanyti VĮP rizikos veiksnius ir gebèti imtis geriausių jos valdymo būdų.

Rizikos veiksniai. Lètinė obstrukcinė plaučių liga (toliau - LOPL) yra patologinè būklè, kuriai būdinga nevisiškai išnykstanti bronchų obstrukcija. Bronchų obstrukcija dažniausiai progresuoja ir yra susijusi su neịprastu uždegiminiu 
plaučių atsaku ị ịkvepiamas kenksmingas daleles ar dujas [8]. Nors LOPL yra viena iš dažniausių gretutinių ligų bei vienas iš pagrindinių pneumonijos išsivystymo rizikos veiksnių, buvo atlikta daug tyrimų, įrodančių, kad esant patvirtintai LOPL diagnozei, gerokai padideja sergančiujju pneumonija mirštamumo rizika [9]. M. Restrepo su bendraautoriais aprašè tyrimą, kuriame nustatè, jog esant patvirtintai LOPL diagnozei, pacientų mirštamumas per 30 ir 90 dienų buvo didesnis, palyginus su tais, kuriems LOPL diagnozè nebuvo nustatyta [10]. Panašias įžvalgas savo tiriamajame darbe pateikè J. Rello su bendraautoriais. Tyrèjai nustatè didesni mirštamumą pacientų, kuriems patvirtinta LOPL diagnozé, kai jiems prireikè dirbtinès plaučių ventiliacijos dèl pneumonijos sukelto kvépavimo funkcijos nepakankamumo, lyginant su tais, kuriems LOPL nebuvo diagnozuotas. Taip pat jie nustatè, jog dèl pneumonijos hospitalizuotiems pacientams, turintiems LOPL, gerokai dažniau prireikè gydymo intensyviosios terapijos skyriuje, o jų lovadienių skaičius buvo kur kas didesnis, lyginant su pacientais, kuriems LOPL nebuvo patvirtinta [11]. Atsižvelgiant ị šių tyrimų išvadas, galima teigti, jog LOPL susijęs ne tik su pneumonijos išsivystymu, bet ir su padidejusiu mirtingumu nuo jos.

Nedaugelis užsienio literatūroje publikuojamų tyrimų analizavo profesijas ir jų poveikį VĮP atsiradimui. J. Almirall ir kt. pastebejo, kad reikšmingą poveikị VİP atsiradimui daro ilgalaikis dulkių poveikis bei dažni aplinkos temperatūros pokyčiai. Tokios dalelès kaip suodžiai, silicio dioksido kristalai, medvilnès dulkès ir kadmis gali turèti ịtakos LOPL paūmèjimui, kuri žinoma kaip vienas iš pagrindinių VỊP rizikos veiksnių [12]. B. Neupane ir kiti, atlikę populiacijos aplinkos taršos poveikio tyrimą, nustate, kad VỊP yra labiausiai paplitusi tarp vyresnių nei 65 metų asmenų, kurie dirbo turèdami ilgalaiki kontaktą su lakiomis cheminėmis medžiagomis, rūkalų dūmais ir ypač metalo pramonès dūmais [13]. M. Loeb ir kiti, tirdami pacientus nuo 65 metų ir vyresnius, pastebejjo, kad rūkalų, metalo pramonès dūmai ir lakiosios cheminès medžiagos buvo modifikuojami rizikos veiksniai, sukèlę sunkesnes komplikacijas ir lèmusieji dažnesnę VỊP sergančiụjų hospitalizaciją [14]. Y. Kohlhammer ir kiti, atlikę sisteminę straipsniu analizę nustatė, kad vieninteliai statistiškai reikšmingi profesiniai rizikos veiksniai, skatinantys VİP atsiradimą, yra metalo pramonès dūmai ir ilgalaikis profesinis kontaktas su dulkèmis [15].

Žinoma, kad gyvenimo būdas lemia didžiają dalị sveikatos, todèl suprantama, kad VİP prevencijai svarbus fizinis aktyvumas. M. Neuman ir kt. atliko 12 metų trukmès prospektyvinị fizinio aktyvumo ir VĮP išsivystymo ryšių tyrimą, ị kurị itraukè daugiau nei 83 tūkstančius JAV moterų, neturinčių lètinių ligų. Tyrimo metu nustatyta, kad mažas fizinis aktyvumas yra VĮP rizikos veiksnys, o fiziškai akty- vesnių moterų rizika susirgti yra 18 proc. mažesnè. Tyrimo rezultatai atskleidè, kad moterys, ilgiau nei 2 valandas per savaitę skyrusios bėgimui, ženkliai rečiau sirgo VỊP, nei tyrimo dalyvès, neturinčios poreikio bėgimui kaip fizinio aktyvumo formai [16].

Nekoreguojami rizikos veiksniai taip pat yra svarbūs ligu etiologijai. Nors ir negalime jų išvengti, svarbu apie juos žinoti, kad rizikos grupių žmonės labiau vengtų koreguojamų rizikos veiksnių. T. Dang ir kt. atliktame prospektyviniame kohortiniame 3000 tūkstančių dèl VĮP hospitalizuotų pacientu tyrime buvo išsamiai palyginti tiriamujų sociodemografiniai, klinikiniai, laboratoriniai, su vaistų vartojimu susiję duomenys. Reikšmingą poveiki ( $31 \%$ daugiau nei kitoje grupeje) VĮP išsivystymui turejjo tik vyresnis amžius (> 75 metai) [17]. Funkcinè būklè taip pat turejjo įtakos VỊP išsivystymui. Funkcinè būklè neretai tiesiogiai koreliavo su vyresniu amžiumi. Prastos funkcinès būklès ir vyresnio amžiaus pacientų grupè buvo pneumonijos pažeidžiamiausia [17]. Šie duomenys gali netiesiogiai reikšti, kad vyresnis amžius yra VĮP rizikos veiksnys. Amžius gali koreliuoti ir su kitais senyvų žmonių rizikos veiksniais. Aktyvus rūkymas daro tiesioginị ir nepriklausomą poveikị plaučių uždegimo rizikai, tačiau jis gali veikti ir netiesiogiai, sukeldamas LOPL, kuris yra gerai žinomas VỊP rizikos veiksnys [14].

Inhaliuojamieji gliukokortikosteroidai (toliau - IGKS) yra vaistai nuo uždegimo, plačiai vartojami kvẻpavimo takų ligoms gydyti. Dèl nustatyto jų veiksmingumo bei saugaus vartojimo profilio, šios klasés vaistai buvo įtraukti ị lètiniu kvėpavimo takų, tokių kaip astma, LOPL gydymo rekomendacijas $[18,19]$. Nustatyta, kad gydant lètines uždegimines plaučių ligas, IGKS sumažina bendrą ligų paūmèjimų dažni ir pagerina gyvenimo kokybę [20], tačiau E. Festic su bendraautoriais ir kiti mokslininkai savo tiriamuosiuose darbuose pastebejjo, jog ilgalaikis IGKS vartojimas LOPL sergantiems pacientams paradoksaliai didinia pneumonijos riziką [21,22].

Žinoma, kad gera dantų ir burnos priežiūra yra svarbi bendrosios sveikatos ir gerovés dalis. Prasta burnos higiena gali sukelti ne tik dantų ertmių ir dantenų ligas. Ji susijusi su padidejjusia širdies ligų, věžio, diabeto kt. išsivystymo rizika [23].Yra tiriamujų darbų, įrodančių stiprią sąsają tarp burnos ertmès ligų ir VỊP išsivystymo rizikos padidejjimo. F. Rodriguez su bendraautoriais apraše tiriamajji darbą, kuriame pastebejjo, jog karštos arba šaltos medžiagos, sukeliančios dantų diesteziją - dantų èduonies ar periodonto ligos rodiklis, dantų protezų dèvejjimas buvo nepriklausomi VI̦P rizikos veiksniai [24]. Kiti mokslininkai pastebejjo, jog prasta burnos higiena gali kelti kvėpavimo takų infekcijų riziką $[25,26]$. İdomu tai, kad prasta burnos sveikata ir burnos bei žarnyno ligos padidino VĮP riziką tiek pagyvenusiems žmonems, tiek visuomenei. Dantų apnašos ir dantų protezai skatina 
kolonizaciją ir gali būti kvėpavimo takų patogenų kaupimosi vieta [24], todèl mūsų praktinè išvada, svarbi VỊP rizikos grupès žmonèms, yra dantų apnašų ir bakterijų kaupimosi prevencija, ypač dèvintiems dantų protezus ir sergantiems dantų èduonies ar periodonto ligomis.

\section{Išvados}

1. Greitas modifikuojamų rizikos veiksnių ịvertinimas ir korekcija galètų sumažinti suaugusių VĮP pacientų, ypač senyvo amžiaus, sergamumą ir mirštamumą.

2. LOPL yra vienas iš pagrindinių VİP išsivystymo rizikos veiksnių, didinantis letalios baigties riziką pacientams, kuriems patvirtinta VĮP diagnozè.

3. Koreguojami rizikos veiksniai, tokie kaip mažas fizinis aktyvumas, nepalankios kvejpavimo takams darbo sąlygos, didina susirgimo VĮP riziką. Yra rizikos veiksnių, kurių koreguoti negalime, vienas tokių yra senyvas amžius.

\section{Literatūra}

1. Almirall J, Bolíbar I, Serra-Prat M, Roig J, Hospital I, et al. New evidence of risk factors for community-acquired pneumonia: a population-based study. Eur Respir J 2008;31(6):1274-1284 . https://doi.org/10.1183/09031936.00095807

2. Ewig S, Torres A. Community-acquired pneumonia as an emergency: time for an aggressive intervention to lower mortality. Eur Respir J 2011;38(2):253-260.

https://doi.org/10.1183/09031936.00199810

3. Musher DM, Thorner AR. Community-acquired pneumonia. N Engl J Med. 2014;371(17):1619-1628. https://doi.org/10.1056/NEJMra1312885

4. Rui P, Kang K. National hospital ambulatory medical care survey: 2015 emergency department summary tables. http://www.cdc. gov/nchs/data/ahcd/nhamcs_emergency/2015_ed_web_tables. pdf.

5. Waterer GW, Rello J, Wunderink RG. Management of community-acquired pneumonia in adults. Am J Respir Crit Care Med 2011;183(2):157-164.

https://doi.org/10.1164/rcem.201002-0272CI

6. Griffin MR, Zhu Y, Moore MR, Whitney CG, Grijalva CG. U.S. hospitalizations for pneumonia after a decade of pneumococcal vaccination. N Engl J Med 2013;369(2):155-63.

https://doi.org/10.1056/NEJMoa1209165

7. Sveikatos statistika. Traumu ir nelaimingu atsitikimu stebèsenos sistemos duomenys. Higienos Institutas. https://stat.hi.lt/ default.aspx?report_id=169

8. Chronic respiratory diseases. WHO.

https://www.who.int/respiratory/copd/definition/en/

9.Feldman C, Viljoen E, Morar R, Richards G, Sawyer L, Mahomed GA. Prognostic factors in severe community-acquired pneumonia in patients without co-morbid illness. Respirology 2001;6(4):323-330. https://doi.org/10.1046/j.1440-1843.2001.00352.x

10. Restrepo MI, Mortensen EM, Pugh JA, Anzueto A. COPD is associated with increased mortality in patients with community-acquired pneumonia. Eur Respir J 2006;28(2):346-351.

https://doi.org/10.1183/09031936.06.00131905

11. Rello J, Rodriguez A, Torres A, Roig J, Sole-Violan J, GarnachoMontero J, et al. Implications of COPD in patients admitted to the intensive care unit by community-acquired pneumonia. Eur Respir J 2006;27(6):1210-1216. https://doi.org/10.1183/09031936.06.00139305

12. Almirall J, Serra-Prat M, Bolíbar I, Palomera E, Roig J, Boixeda R, Bartolomé M, de la Torre M, Parra O, Torres A. Professions and working conditions associated with community-acquired pneumonia. Arch Bronconeumol 2015;51(12):627-631.

https://doi.org/10.1016/j.arbres.2014.10.003

13. Hnizdo E, Storey E. Occupational exposure to gases, fumes, or chemicals and risk of community-acquired pneumonia. Am J Respir Crit Care Med 2010;182 (8):1087-1088

https://doi.org/10.1164/ajrccm.182.8.1087

14. Loeb M, Neupane B, Walter SD, Hanning R, Carusone SC, Lewis D, et al. Environmental risk factors for communityacquired pneumonia hospitalization in older adults. J Am Geriatr Soc 2009;57(6):1036-1040. https://doi.org/10.1111/j.1532-5415.2009.02259.x

15. Kohlhammer Y, Schwartz M, Raspe H, Schäfer T. Risk factors for community acquired pneumonia (SAP). A systematic review. Dtsch Med Wochenschr 2005;130(8):381-386. https://doi.org/10.1055/s-2005-863061

16. Neuman MI, Willett WC, Curhan GC. Physical activity and the risk of community-acquired pneumonia in US women. Am J Med 2010;123(3):281.

https://doi.org/10.1016/j.amjmed.2009.07.028

17. Dang TT, Eurich DT, Weir DL, Marrie TJ, Majumdar SR. Rates and risk factors for recurrent pneumonia in patients hospitalized with community-acquired pneumonia: population-based prospective cohort study with 5 years of follow-up. Clin Infect Dis 2014;59(1):74-80.

https://doi.org/10.1093/cid/ciu247

18. Hartley BF, Barnes NC, Lettis S, Compton CH, Papi A, Jones P. Risk factors for exacerbations and pneumonia in patients with chronic obstructive pulmonary disease: a pooled analysis. Respir Res 2020; 21(1):5.

https://doi.org/10.1186/s12931-019-1262-0

19. Global strategy for asthma management and prevention. Global Initiative for Asthma 2017. https:/ginasthma.org/wp-content/ uploads/2019/04/wmsGINA-2017-main-report-final_V2.pdf.

20. Global strategy for the diagnosis, management, and prevention of chronic obstructive pulmonary disease.Global Initiative for Chronic Obstructive Lung Disease 2018. https:/goldcopd. org/wp-content/uploads/2017/11/GOLD-2018-v6.0-FINALrevised-20-Nov_WMS.pdf 
21. Festic E, Scanlon PD. Incident pneumonia and mortality in patients with chronic obstructive pulmonary disease. A double effect of inhaled corticosteroids? Am J Respir Crit Care Med 2015;191(2):141-148.

https://doi.org/10.1164/rccm.201409-1654PP

22. Suissa S, Patenaude V, Lapi F, Ernst P. Inhaled corticosteroids in COPD and the risk of serious pneumonia. Thorax 2013;68(11):1029-1036.

https://doi.org/10.1136/thoraxjnl-2012-202872

23. Frank C. DDS medicall review. Written by the health line editorial team and Jacquelyn Cafasso 2018. https://www.healthline. com/health/dental-and-oral-health

24. Rodriguez F, Bolíbar I, Serra-Prat M, Palomera E, et al. Poor oral health as risk factor for community-acquired pneumonia. J Pulm Respir Med 2014;4:5.

https://doi.org/10.4172/2161-105X.1000203

25. Mojon P, Budtz-Jørgensen E, Michel JP, Limeback H. Oral health and history of respiratory tract infection in frail institutionalised elders. Gerodontology 1997;14(1): 9-16. https://doi.org/10.1111/j.1741-2358.1997.00009.x

26. Terpenning MS, Taylor GW, Lopatin DE, Kerr CK, et al. Aspiration pneumonia: dental and oral risk factors in an older veteran population. J Am Geriatr Soc 2001;49(5): 557-563.

https://doi.org/10.1046/j.1532-5415.2001.49113.x

\section{RISK FACTORS FOR COMMUNITY-ACQUIRED PNEUMONIA IN ADULTS}

\section{Skalskis, S. Filipauskas, G. Gečaitė}

Keywords: community acquired pneumonia, pneumonia, risk factors, adults.

Summary

The aim of this study was to evaluate, systematize, and analyze data from the scientific literature on the epidemiology of community-acquired pneumonia (CAP) and risk factors for adult patients. This systematic review analyzes 22 full text articles. Based on the results of the selected articles, we can conclude that the development of CAP is contributed by a number of adjustable and uncorrected risk factors. Rapid assessment and correction of modifiable risk factors could reduce morbidity and mortality in adult patients with CAP, especially in the elderly. COPD is one of the major risk factors for the development of CAP and also one of the main factors increasing the risk of fatal outcome in patients with a confirmed diagnosis of CAP. Adjusted risk factors such as low physical activity, unfavorable airway working conditions increase the risk of developing CAP.

Correspondence to: iljaskalskis@gmail.com

Gauta 2020-05-14 